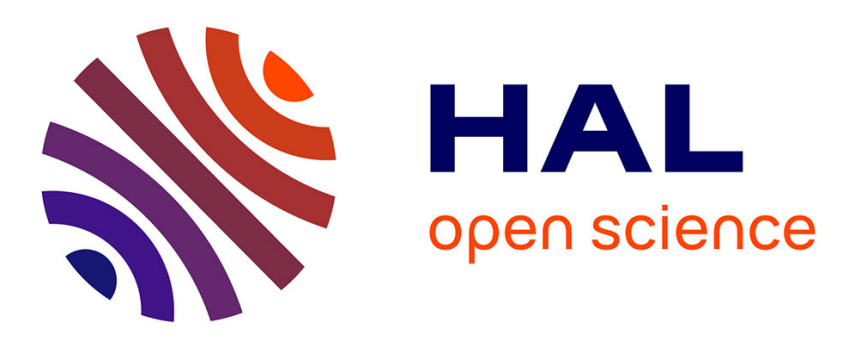

\title{
Transition Periods in the Diurnally-Varying Atmospheric Boundary Layer Over Land
}

Wayne Angevine, John Edwards, Marie Lothon, Margaret Lemone, Simon

Osborne

\section{- To cite this version:}

Wayne Angevine, John Edwards, Marie Lothon, Margaret Lemone, Simon Osborne. Transition Periods in the Diurnally-Varying Atmospheric Boundary Layer Over Land. Boundary-Layer Meteorology, 2020, 177 (2-3), pp.205-223. 10.1007/s10546-020-00515-y . hal-03036402

\section{HAL Id: hal-03036402 https://hal.science/hal-03036402}

Submitted on 14 Dec 2020

HAL is a multi-disciplinary open access archive for the deposit and dissemination of scientific research documents, whether they are published or not. The documents may come from teaching and research institutions in France or abroad, or from public or private research centers.
L'archive ouverte pluridisciplinaire HAL, est destinée au dépôt et à la diffusion de documents scientifiques de niveau recherche, publiés ou non, émanant des établissements d'enseignement et de recherche français ou étrangers, des laboratoires publics ou privés. 
1 Transition Periods in the Diurnally-Varying Atmospheric Boundary

2 Layer Over Land

3

4 Wayne M. Angevine*

5 CIRES, University of Colorado, and NOAA Chemical Sciences Division, Boulder, Colorado USA.

6 E-mail:Wayne.M.Angevine@noaa.gov

7

8 John M. Edwards

9 Met Office, Exeter, UK

10

11 Marie Lothon

12 Laboratoire d'Aérologie, University of Toulouse, CNRS, UPS, Toulouse, France

13

14 Margaret A. LeMone

15 National Center for Atmospheric Research, Boulder, Colorado USA

16

17 Simon R. Osborne

18 Met Office, Cardington, UK

19

20 Abstract

21 The atmospheric boundary layer undergoes transitions between stable and convective states. Over

22 land, in undisturbed conditions, these transitions occur daily in the morning and late afternoon or

23 early evening. Though less well studied and presenting more challenges than the fully stable and 
24 fully convective states, such transitions have been the subject of growing interest over the last few

25 decades. During transitions, all forcings are weak, and few simplifications are possible. Factors

26 such as terrain, radiation, advection, and subsidence can seldom be safely neglected. In this paper,

27 we review research on transitions over recent decades, with an emphasis on work published in

28 Boundary-Layer Meteorology. The review is brief and inevitably reflects the interests and views of

29 the authors.

30 Keywords Afternoon transition - Evening transition - Morning transition · Boundary-layer field

31 studies $\cdot$ Boundary-layer simulation

\section{Introduction}

33 Over land under clear skies and in the absence of any synoptic disturbance, the atmospheric

34 boundary layer (ABL) is often deep and strongly turbulent during the day, shallow and weakly

35 turbulent at night. In between, the ABL undergoes morning and afternoon/evening transitions.

36 Those transitions have been the subject of considerable research in the last 25 years, much of which

37 has been published in Boundary-Layer Meteorology. Figure 1 is a schematic showing a large-eddy

38 simulation (LES) of the diurnal cycle of an idealized mid-latitude ABL, see the caption for more

39 details. Shown are the times of sunrise, crossover (change of sign of the surface buoyancy flux),

40 onset of convective turbulence at a height of $200 \mathrm{~m}$, rising of the entrainment zone and growth of

41 the mixed layer during the day, cessation of growth and eventual shrinkage during the afternoon,

42 and the times of crossover and sunset during the evening transition, followed by the growth of the

43 stable boundary layer (SBL), and the subsidence of the capping inversion overnight. These features

44 are discussed in more detail below. We do not provide precise definitions of the transitions

45 because they themselves evolve through the literature reviewed. Each section addresses definitions

46 as appropriate. 
47 Motivations for the study of transitions are various. For air-quality forecasts and analyses, the 48 timing of changes in the depth of mixing with respect to time-varying emissions is important. The 49 evening transition is key to the evolution of the low-level jet (Smith et al. 2019), which often 50 influences severe weather. Fog and frost forecasting depend on understanding the evening 51 transition (Boutle et al. 2018; Price 2019). 

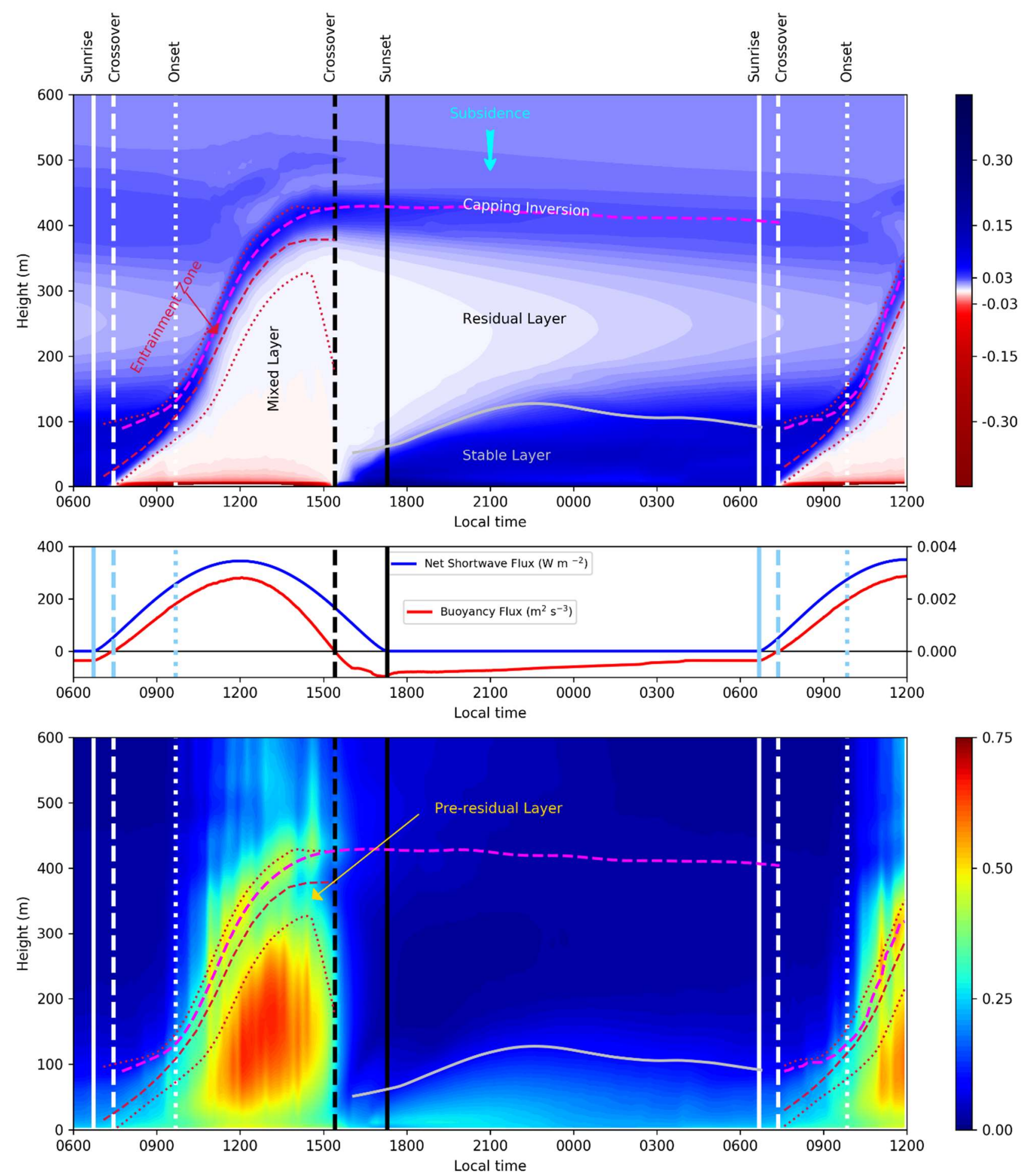

52 Fig. 1 A schematic illustration of the diurnal cycle of the ABL derived from a large-eddy simulation. a The evolution

53 of the vertical gradient of the horizontally-averaged potential temperature, $\theta$, with height above the surface. Vertical

54 white lines indicate the times of sunrise, crossover and onset during the morning transition, while vertical black lines

55 show the times of crossover and sunset during the evening transition. The light grey line marks the top of the stable 
boundary layer, defined as the height at which the linearly-extrapolated horizontally-averaged buoyancy flux becomes

57 zero. The dashed magenta line marks the height of the elevated maximum of the gradient of $\theta$. The crimson dashed line

58 indicates the height of the minimum of the buoyancy flux during the period when the boundary layer is unstable.

59 Crimson dotted lines mark the upper and lower boundaries of the entrainment zone during the same period, the former

60 defined as the lowest height above that of the minimum of the buoyancy flux at which the absolute value

61 of the buoyancy flux first falls below $5 \%$ of the surface value, and the latter as the lowest height at which the buoyancy

62 flux changes sign. The figure also shows the rising of the entrainment zone through the morning, the development of

63 the well-mixed layer, and, after the evening transition, the development of the nocturnal stable boundary layer, the

64 radiative stabilization of the residual layer, and the subsidence of the capping inversion. $\mathbf{b}$ The evolution of the net

65 downward shortwave flux at the surface (left axis) and the surface buoyancy flux (right axis). $\mathbf{c}$ The evolution of the

66 square root of the variance of the vertical velocity with height. Lines as in a and also showing the pre-residual layer.

68 Transitions are complex because many processes are roughly equally important, and the

69 simplifications and approximations that work well for the fully convective or the fully stable

70 boundary layer do not apply. In budget analyses, more terms must be retained, often including

71 direct radiative heating of the air, mixing due to shear, and advection. Stationarity may not apply.

72 Full descriptions of the surface energy balance and of the energy balance at the top of the ABL are

73 not included in this review, reflecting the contents of the literature we are considering.

74 Most of our increased understanding of the transition periods has been enabled by ground-based

75 remote sensing measurements (Wilczak et al. 1996), since measurements at the surface provide

76 only a limited perspective. The ability to view continuously the full depth of the boundary layer

77 and especially its upper region is critical to understanding transitions. Traditional tall-tower

78 measurements and observations taken by aircraft have also contributed. 
While this should not be mistaken for a full description of the diverse possibilities, considering the

80 diurnal cycle is an improvement over looking only at the fully convective and fully stable states.

81 Throughout this review, we remain mindful of ways in which the real atmosphere frequently

82 departs from the idealization. Horizontal inhomogeneity of the surface, land use, soil and

83 vegetation properties has strong impacts. Coasts create land and sea breezes. Terrain induces

84 mountain and valley breeze systems. The daytime ABL is not always strongly turbulent, and the

85 nocturnal boundary layer is not always shallow.

86 The depth of the boundary layer is an ambiguous but important variable in discussions of the ABL

87 in general and transition periods in particular. When the convective boundary layer (CBL) is

88 topped by a well-defined increase in virtual potential temperature, its depth is fairly precisely

89 measured by any of several definitions (e.g. turbulence intensity, virtual-temperature profile,

90 virtual-temperature-flux profiles, or Richardson number) (LeMone et al. 2013). The depth of the

91 stable boundary layer is fundamentally more difficult to define, since the turbulence-intensity

92 profile may have a variety of shapes. Clouds add another level of complexity. Measurements of

93 the depth of an aerosol layer, for example by lidar, can be useful but must be carefully examined to

94 avoid mistaking the residual layer for the current boundary layer (Hogan et al. 2009; Tucker et al.

95 2009). The preferred technique is to measure the profile of vertical velocity variance, but this

96 approach can produce ambiguous results because of gravity waves near the boundary-layer top

97 (Lothon et al. 2009). Whether the ABL is stable or convective, some definitions can be readily

98 derived from NWP or LES model output, but rarely or with difficulty in observations. Throughout

99 this review, we will use the terms "boundary-layer depth" and "boundary-layer top" as if they were

100 well-defined, without tediously acknowledging all of this complexity every time the term comes

101 up. 
102 The review proceeds as follows: First, the morning and afternoon/evening transitions as seen in

103 observations are described in Sects. 2 and 3. In Sect. 4, key processes involved are discussed, 104 including entrainment, radiation, advection and subsidence, length and time scales, and clouds.

105 Sections 5 and 6 describe the current understanding provided by LES and mesoscale numerical 106 weather prediction (NWP) models respectively, and the challenges that continue to arise in the 107 modelling of the diurnal cycle. Finally, we provide an outlook and thoughts on needs for ongoing 108 research.

\section{The Morning Transition in Observations}

110 The role of mixing from above the near-surface layer relative to heating from the surface was an

111 important question in early research on the morning transition. Data from the Cabauw tower in the

112 Netherlands were used by Driedonks (1982) to test analytical models of the early-morning

113 boundary-layer growth. He recognized that entrainment was important in many cases, and his

114 preferred model included a term proportional to the surface stress, based on theory provided by

115 Tennekes (1973). Aircraft data in Australia were used by Coulman (1978) to test predictions of 116 morning boundary-layer growth, with mixed results. He found that entrainment was probably

117 important, and that estimating some parameters with suficient precision was not always possible, 118 particularly the inversion temperature gradient. Several expressions were provided by Garratt 119 (1992) along with a useful figure showing the change in potential-temperature profile for a 120 transition driven by surface heating vs. shear. A large dataset was examined by Angevine et al. 121 (2001) using data from the Cabauw tower (van Ulden et al. 1996) and radar wind-profiler data from 122 the Cabauw site and from the Flatland (Bondville, Illinois) site (Angevine et al. 1998). They 123 defined two milestones in course of the transition, "crossover" (when the surface buoyancy flux 124 first becomes positive) and "onset" (when convective turbulence is first detected at $200 \mathrm{~m}$ above 
125 the ground). Sunrise was used as a reference time (Fig. 1). The most interesting discovery from 126 this study was that the time required to erode the stable layer from below, using the measured heat 127 flux and ignoring entrainment, was much longer than the time over which the layer was actually 128 eroded. In other words, the surface heat flux was insufficient to warm the stable layer in the 129 observed time. The conclusion was, and remains, that much of the warming arises from 130 entrainment at the top of the eroding stable layer. The data showed a situation more like Garratt's 131 Fig. 6.7b for a shear-driven transition. This was foreshadowed by Wyngaard (1983) in a brief 132 remark indicating that only a small heat flux was required to switch from a stable to a convective 133 layer.

134 We must caution that the definition of entrainment used in the above papers is imprecise. 135 Formally, entrainment is "The process by which turbulent fluid within a mixed layer incorporates 136 adjacent fluid that is nonturbulent, or much less turbulent." (American Meteorological Society 137 Glossary of Meteorology). However, in the context of the morning transition, within a statically 138 stable layer, the turbulent state of the air at each level is often not known. Some of the air that is 139 mixed to produce a near-neutrally-stratified layer may already have been turbulent and therefore 140 formally part of the boundary layer. The unknown turbulent state makes the formal definition 141 difficult to apply rigorously.

142 It should be noted that the measurements used by Angevine et al. (2001) were influenced by a 143 general effort in previous years to understand and exploit the capabilities of ground-based remote 144 sensing instruments (e.g. (Angevine et al. 1994; Beyrich et al. 1995; Carter et al. 1995).

145 A six-year dataset from the rural resarch site at Cardington in central England was used by 146 Lapworth (2006) to examine the morning and evening transitions, with an emphasis on wind speed 147 and forecasting rules. He confirmed the finding that most of the warming during the morning 
148 transition was due to mixing from above. Before crossover, the warming is better described as 149 eddy diffusion rather than entrainment, since the boundary-layer top may not be rising. The near150 surface air temperature is controlled by the balance between radiative cooling and turbulent mixing, 151 which, under weak to moderate stability, is continuous. As the radiative cooling decreases, the 152 turbulent heat flux from above warms the near-surface layer, before the surface heat flux becomes 153 positive (upward).

154 Figure 2 shows observed soundings during a morning transition at Cardington. Entrainment is 155 evidenced by cooling in the upper part of the growing boundary layer in the progression of 156 observed soundings, especially between 0400 and 0700 UTC for example. Profiles from an 157 operational NWP model are also shown. The simulated boundary layer is consistently too cool and 158 too shallow, probably because of insufficient entrainment. Advection is important in most 159 individual cases, but is not observed, so attribution of the changes in profiles due to entrainment is 160 suggestive rather than conclusive; see Angevine et al. (2001) for more cases and discussion of their 161 variations.

162 An interesting feature of the morning transition is a peak in the time series of near-surface specific 163 humidity that is sometimes observed, e.g. (LeMone et al. 2002). When transpiration by vegetation 164 becomes significant while the mixed layer is still shallow, the humidity may exhibit a local 165 maximum, and then decline when the mixed layer grows. The morning peak is not seen in the 166 Flatland or Cabauw data of Angevine et al. (2001), but was seen at Cabauw on the day used by 167 Holtslag et al. (1995), and seems therefore to depend on the season and vegetation type. This has 168 been further studied for the afternoon/evening transition by Blumberg et al. (2019).

169 It is notable that multi-day averages are necessary to make understandable behaviour emerge from 170 data. Individual days exhibit a wide range of behaviour, dominated by advection, which is hardly 
171 ever negligible (Baas et al. 2010), but sometimes averages out over multiple days (Betts et al.

172 1996). Even mild terrain can produce phenomena that overwhelm column-wise analyses, as was

173 found by Lenschow et al. (1979). Some influence of heterogeneity cannot be ruled out in the

174 Flatland and Cabauw cases, although the Flatland site in particular is extremely uniform for a land

175 site.

176 Further development of observational equipment and techniques continues to add to our knowledge

177 of the morning transition. Wildmann et al. (2015) conducted a study with a small remotely-piloted

178 aircraft, emphasizing the scaling behaviour of variances compared with theory, and they include a

179 thorough discussion of uncertainties and challenges.

$180 \quad 3$ Afternoon and Evening Transition in Observations

181 From a surface perspective, the boundary layer changes from unstable to stable in the "evening,"

182 some time near sunset, but looking at the boundary-layer top, changes happen much earlier in the 183 day. This has led to a lack of clarity and consensus in terminology. In this review, we refer to the

184 afternoon or evening transition according to the terms used by the cited papers. Many of these 185 terms are illustrated in Fig. 1. In general, "afternoon transition" denotes the period when the surface 186 buoyancy flux decreases (from midday to sunset), and "evening transition" refers to the period near 187 sunset including the change of sign of the surface buoyancy flux. A sunset-relative frame of 188 reference was used by Wingo et al. (2015). In complex terrain, local sunset is a key time, 189 especially when slopes are steep (Nadeau et al. 2011). In Fig. 1, we have indicated sunset and 190 crossover, newly defined here for the evening transition as the time when the surface buoyancy flux 191 changes sign from upward to downward, the opposite of morning crossover. 
192 Mahrt (1981) made an early observational study of the "early evening" transition based on data

193 from the Wangara (Australia) study, emphasizing the behavior of the wind and the low-level jet.

194 Mahrt observed that the wind changes began well before sunset. Many studies of the evening

195 transition consider slightly or moderately complex terrain. Acevedo et al. (2001) and Mahrt (2017)

196 emphasized the evolution of temperature and wind through three phases. The cooling is small at the

197 start (before zero flux), greater in the second phase (around zero net radiation), and decreases again

198 after sunset. The wind decelerates, changes to calm or local drainage, and evolves toward regional

199 drainage or synoptic flow, as also shown by LeMone et al. (2003), Busse et al. (2012), Román-

200 Cascón et al. (2015), and Nilsson et al. (2016a). Those phases all depend on the characteristics of

201 the studied sites. A peak in the time series of specific humidity may also be present, and is

202 dependent on the season, location, and crop behavior (Blumberg et al. 2019).

203 Recent works have highlighted new features like the counter-gradient flux (Blay-Carreras et al.

204 2014a), caused by a delay between the times when the surface flux changes sign and when the

205 temperature gradient changes sign.. It has been shown to be partly related to the eddy turnover

206 time, and dependent on the vegetation cover and height (Jensen et al. 2016). Also the lifted

207 temperature minimum is worth mentioning (Blay-Carreras et al. 2015), that is, a minimum of 208 temperature at $0.1-1 \mathrm{~m}$ above the surface.

209 A detailed study by Grant (1997) used data from tethered balloon equipment at the Cardington site

210 to describe the latter part of the transition period, after the surface buoyancy flux had changed to

211 negative (downward). Grant showed profiles and spectra to explore the applicability of proposed

212 scaling frameworks during the evening transition. Further data from the same site and similar

213 equipment were used by Edwards et al. (2006). Observations of turbulent kinetic energy near the

214 surface were used by Nadeau et al. (2011), who fitted a simple analytical model which 
215 approximately showed a $t^{-2}$ power-law decay of turbulent kinetic energy (TKE) early in the 216 transition, and $t^{-6}$ later ( $t$ being time).

217 Observations through the depth of the boundary layer in the afternoon and evening were rare until 218 ground-based remote sensing instruments became available. The first full analysis was undertaken 219 by Grimsdell et al. (2002) using wind-profiling radar observations in conjunction with surface-flux 220 measurements. They found that the height of the boundary layer decreases in the afternoon, 221 starting some hours before sunset. The explanation is this: as solar heating of the surface begins to 222 decline, and the air continues to warm, thermals become less vigorous. Since the bulk of the 223 boundary layer is roughly adiabatic, the weaker thermals can still reach the boundary-layer top at 224 first. Meanwhile, several other processes are at work, and all of these tend to reduce the height of 225 thermals. Subsidence directly lowers the boundary-layer top. Subsidence, shear-driven 226 entrainment, and direct radiative heating all act to stabilize the upper part of the boundary layer. In 227 the case of subsidence, regime selection is at work: If large-scale upward motion is present, clouds 228 and precipitation often form, and these days are seldom considered for further case study analysis.

229 Direct measures of turbulence show the decreasing top height, while indirect measures, particularly 230 aerosol layer height, may not. Since the boundary layer is defined as being in recent contact with 231 the surface (Stull 1988; LeMone et al. 2019), the direct turbulence measurement is preferred 232 (Tucker et al. 2009; Barlow et al. 2011; Harvey et al. 2013; Manninen et al. 2018).

233 Lidar observations of the boundary layer over London, UK covering several full diurnal cycles 234 were published by Barlow et al. (2011). The urban boundary layer has additional complexity not 235 seen in simpler situations, but some of its characteristics are similar. Long lidar datasets from two 236 sites were analyzed by Manninen et al. (2018). 
237 The Boundary Layer Late Afternoon and Sunset Turbulence (BLLAST) field study was focused on

238 these transitions. It provided a comprehensive set of measurements by all types of instruments and

239 platforms. Unlike most earlier studies, the BLLAST study embraced the challenge of complex

240 terrain and heterogeneous land use. Lothon et al. (2014) provides an overview, early results, and a

241 rich bibliography. The project started with careful definitions, and in addition to measurements,

242 incorporated theory and modelling. Frequent and continuous observations through the whole depth

243 of the boundary layer allowed more complete analysis than had previously been possible. The

244 decay of TKE in a vertically resolved sense, and the ways in which turbulent length scales change,

245 were particular foci.

246 In terms of the scaling of turbulence within the boundary layer, the BLLAST study results from

247 aircraft (Lothon et al. 2014; Darbieu et al. 2015) and near-surface measurements (Nilsson et al.

248 2016a; Nilsson et al. 2016b) indicated that statistics of turbulence on days with weak shear are

249 quasi-stationary until late afternoon. Shear delays the decay, or even prevents decay if strong

250 enough (Pino et al. 2006). While the decay remains slow enough for statistics to be quasi-

251 stationary, the turbulence structure does not evolve substantially, and remains scaled with the

252 boundary-layer depth. Later in the afternoon, the decay accelerates and the turbulence structure

253 departs from CBL scaling. The decay was found to start from the top (Darbieu et al. 2015),

254 although this strongly depends on the shear at surface and at boundary layer top. Consistent with

255 this, Nilsson et al. (2016b) used a simple model to identify a region of reduced turbulence that

256 appears earlier in the upper part of the boundary layer, before the stable layer develops, and

257 expands downward with time. They described this as a "pre-residual" layer. Scaling by the 258 buoyancy flux clearly becomes questionable as it approaches zero. 
260 The afternoon transition is nearly unforced; all contributing processes are weak. The morning

261 transition is forced by the rising sun, but this forcing is surprisingly weak as well. Many processes

262 influence the boundary layer through the diurnal cycle, and the key challenge to understanding is

263 the need to include all relevant processes. Turbulent eddy sizes and time scales change.

264 Entrainment at the boundary-layer top and mixing of entrained air play important roles. Advection

265 is almost always important when examining individual days and hours, and is difficult to estimate.

266 Direct radiative heating or cooling of the air (as opposed to heating or cooling of the surface) is

267 often small, but cannot be safely neglected during transitions. When fluxes or turbulent energy are

268 changing rapidly, methods of analysis that neglect time rates of change may fail. Clouds may

269 affect the profiles of mean and turbulent quantities, especially near the top of the boundary layer.

270 This section describes these processes in more detail.

271 4.1 Eddy Length and Time Scales

272 Time scales are fundamental to transitions, in fact to the idea of transition itself. Some relevant

273 time scales include the eddy turnover time, the time required for the boundary-layer height to 274 change by a given fraction, and the time required for the surface buoyancy flux to change by a 275 given fraction (or to reverse sign). Around midday, the eddy turnover time (10-20 min) is much 276 shorter than the time scale of the evolution of the boundary-layer height, which changes only

277 slowly. In the morning growth phase, however, the boundary layer may grow as rapidly as a 278 thermal rises (Sorbjan 1997).

279 The time scale for turbulence to decay is important in the afternoon and evening, and depends on 280 the eddy size (Pino et al. 2006; Lothon et al. 2014). Larger eddies decay more slowly, leading to 281 an effective increase in the length scale above the surface layer. 
282 The impact of variation in surface fluxes on time scales in the CBL was explored by Van Driel et 283 al. (2011) in an idealized framework. They made several interesting findings: the time scale for 284 changes in the boundary-layer depth is very long, of order $10 \mathrm{~h}$, because it is controlled by the 285 entrainment velocity. A phase lag between the changing surface flux and the mixed-layer height is 286 due to these differing time scales. For rapidly varying fluxes, the production and dissipation of 287 TKE become important. Their simulations included subsidence and radiative cooling specifically 288 tuned to produce a steady boundary-layer depth and temperature. The application of these results 289 to transitions is challenging, because, for example, the entrainment velocity during the morning 290 transition can be very large (shortening the time scale). . Subsidence and other processes that are 291 roughly in balance at midday, allowing the boundary-layer depth to remain approximately constant, 292 become unbalanced when the surface flux permanently weakens in the afternoon, resulting in rapid 293 changes of the boundary-layer depth. Nonetheless, the concept of competing time scales and 294 transfer functions introduced by Van Driel et al. (2011) is a promising framework for future 295 exploration.

296 Another important time scale from a practical point of view is the averaging time required in 297 processing turbulence measurements, whether from a sonic anemometer or a remote sensor. If 298 important changes happen during the averaging time, the measurements are hard to interpret (Mahrt 299 1981; Grant 1997). On the other hand, averaging over too short a time gives noisy and excessively 300 uncertain results, and can lead to systematic underestimation of fluxes.

301 Length scales and their variation are also vital to understanding boundary-layer behaviour. With 302 the dataset from the BLLAST study, Darbieu et al. (2015) found that the length scales of turbulence 303 remain scaled with the boundary-layer depth until late afternoon (more precisely until about 0.75 304 times the decay-forcing time scale). Later, they observed a sharp decrease of the length scale in the 
305 surface layer, and an increase of the length scale above. The changes occurred first at the top of the

306 boundary layer, although this depends on shear.

$307 \quad 4.2$ Entrainment

308 As described in sections 2 and 3 above and sections 5 and 6 below, entrainment at the boundary-

309 layer top is critical to the transitions. In the morning, most of the warming during the transition is

310 due to mixing from above, either from within the upper part of the boundary layer or from

311 entrainment. In the afternoon, entrainment is one of the processes that causes warming in the upper

312 part of the boundary layer and thereby reduces the depth of mixing. Entrainment is a complex

313 topic that deserves a whole review by itself; see Angevine (2008) for further discussion and

314 references. It is particularly worth noting that entrainment relationships depend strongly on the

315 interpretive framework, e.g. Liu et al. (2017). Figure 2 shows the importance of entrainment in the

316 morning transition, and insufficient entrainment appears to be the cause of the cool and shallow

317 bias in the morning boundary layer in the UKV NWP model. 


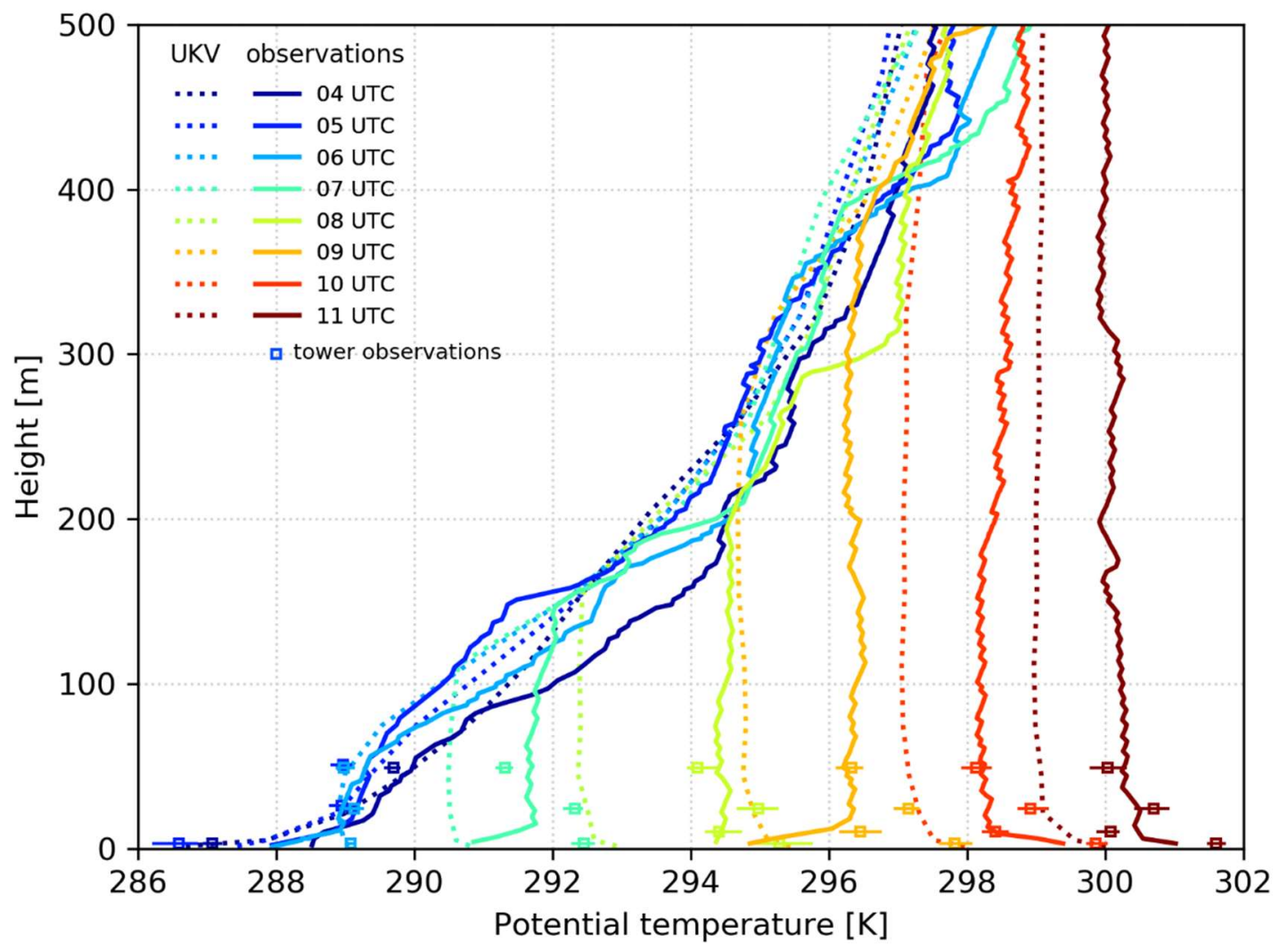

318 Fig. 2 Profiles of potential temperature at the Cardington field site during the clear-sky morning of 19 July 2016.

319 Radiosonde ascents launched on each hour are shown as solid lines, together with tower sensors (square points) at 2 m,

$32010 \mathrm{~m}, 25 \mathrm{~m}$ and $50 \mathrm{~m}$; horizontal bars on the mast data show variations of $+/-5$ mins centred on each hour. Model data

321 (dotted lines) are the instantaneous hourly forecast profiles from the Met Office UKV operational $1.5 \mathrm{~km}$ grid spacing 322 model, initialized at 0300 UTC.

324 A nearly adiabatic residual layer often exists above the nocturnal boundary layer. In the morning, 325 when the growing boundary layer reaches the base of the residual layer, its growth rate increases 326 until the residual-layer top is reached (Deardorff 1974; Sorbjan 1996; Blay-Carreras et al. 2014b).

327 It is useful to note, however, that the residual layer is not simply the remains of the previous day's 328 mixed layer at the same location; because ofdifferential advection, the mixed layer found in the 329 morning above a certain site was likely formed somewhere else. 
331 Experience with setting up cases for single-column model (SCM) and LES comparisons has shown 332 that advection is rarely negligible, even at nearly ideal sites. Measurements of advection are 333 difficult or impossible. The best that can be done is to estimate advection terms from observations 334 at levels that are thought not to be affected by turbulent mixing, or to use output from mesoscale 335 models (Barr et al. 1997; Angevine 1999). Estimates of subsidence are at least as problematic. 336 Efforts involving many dropsondes have succeeded in producing subsidence measurements for the 337 simplest possible situation over water (Bony et al. 2018). It should be noted, however, that 338 comparisons between LES and other types of models using the same forcings are not subject to 339 these uncertainties.

340 Baas et al. (2010) discuss the issue of specifying forcing (advection) for SCM studies. They 341 demonstrate strong impacts on the formation of the low-level jet (an evening-transition issue) from 342 different plausible specifications of advection. These differences make it difficult to determine 343 which vertical mixing formulation is best. They also show that a composite case, constructed by 344 averaging several similar cases, removes some of the "noise" and allows for clearer conclusions. 345 Different choices of forcing, all from plausible sources, had a strong impact on shallow cumulus 346 simulations shown by Angevine et al. (2018). Averaging over many cases was done by Angevine et 347 al. (2001) to understand the morning transition. Systematic advection can mislead the analyst 348 despite averaging. For example, in the central United States, the prevailing wind direction is 349 southerly (warm and moist) in summer and northerly in winter, so advection cannot be expected to 350 average out within a season.

351 The effects of subsidence (Blay-Carreras et al. 2014b) and advection (Pietersen et al. 2015) were 352 studied for some BLLAST cases. At the BLLAST site, there was a persistent diurnal pattern of 
353 subsidence, induced by the nearby mountain range and accentuated by moist convection over the 354 mountains.

355 4.4 Radiation

356 Vertical turbulent heat fluxes driven by net radiation at the surface play a substantial role in the

357 diurnal evolution of the boundary layer, but direct atmospheric radiative heating is also relevant.

358 Radiative cooling at cloud top can generate turbulence and affect the entrainment rate (Stevens

359 2002; de Lozar et al. 2015). Clear-sky radiative processes have received less attention, but can play

360 a significant role in transitions. Longwave radiative cooling erodes the capping inversion and

361 accelerates the growth of the boundary layer through the morning transition (Edwards et al. 2014).

362 Radiative cooling near the surface during the evening transition stabilizes the developing stable

363 boundary layer and suppresses turbulence (Garratt et al. 1981; Ha et al. 2003). In near-calm

364 conditions radiation can be the dominant process determining the temperature profile (Savijarvi

365 2006; Edwards 2009). Longwave radiative cooling rates vary on short length scales near the

366 surface, so poor vertical resolution can produce incorrect results in either observations or models

367 (Ha et al. 2003; Edwards 2009; Steeneveld et al. 2010).

368 Aerosols in the boundary layer may have large effects on radiative heating or cooling when the 369 aerosol loading is significant or the aerosols are strongly absorbing. Aerosol layers within or above 370 the boundary layer reduce the net radiation reaching the surface (Barbaro et al. 2014; Liu et al. 371 2019), thereby affecting transition timing. Aerosols within the boundary layer or the residual layer 372 can directly heat those layers enough to affect timing as well. The effects are complex and subtle 373 because the sun is low in the sky during transitions. Barbaro et al. (2014) give a detailed discussion 374 of these effects, supported by model studies of two observed cases. 
376 Clouds are very common at the top of the boundary layer. The University of Washington Cloud

377 Atlas (https://atmos.uw.edu/CloudMap/index.html; accessed 15 March 2019) shows that 26\% of

378 land and $55 \%$ of the oceans is covered with low cloud on an annual average basis. Most of these

379 clouds are in the boundary layer. Nonetheless, strongly cloud-influenced conditions are commonly

380 avoided or selected against in boundary-layer field research. During the morning transition,

381 Angevine et al. (2001) noted that the most extreme day-to-day variations in timing were found on

382 days with cloud. In their data from the Flatland site, cloud-free days showed more rapid increases

383 in temperature than cloudy days, but no systematic differences were found between cloud-free and

384 cloud-influenced days at Cabauw. In the afternoon, Grimsdell et al. (2002) found little systematic

385 influence of clouds. Over water, where the diurnal cycle is damped, Pennell et al. (1974) and

386 LeMone (1978) found little influence of clouds on subcloud-layer TKE budgets. Brown et al.

387 (2002) found that subcloud-layer buoyancy-flux profiles were insensitive to cloud cover. In all of 388 these analyses, regime selection probably prevented strong cloud influences.

389 An interesting and complex but not uncommon case is presented by Hogan et al. (2009). A thin

390 stratocumulus layer in the early morning is replaced by a convective boundary layer with shallow

391 cumulus. Radiative cooling in the stratocumulus layer produces mixing, which must affect the

392 timing of the morning transition. Similar cases probably arise commonly, and deserve further

393 exploration. Clouds and their effects are also seen in the data of Harvey et al. (2013) and 394 Manninen et al. (2018).

\section{Transitions in large-eddy simulations and direct numerical simulations}


Large-eddy simulations of transitions are challenging because they require both fine resolution and

397 large domains, and are thus computationally expensive (Beare 2008). Several LES studies of

398 transitions have been done, however. Beare (2008) produced simulations of the morning transition

399 by starting with a small, finely resolved domain and expanding to a larger, more coarsely resolved

400 domain partway through the transition. These simulations started at the time of heat-flux

401 crossover, so they describe the late phase of the transition. Beare found a shallow convective

402 boundary layer with penetrating, entraining updrafts under the remnant stable layer, which he

403 named the "mixed CBL-SBL state". The morning transition in the third GEWEX Atmospheric

404 Boundary Layer Studies (GABLS3) case was simulated by Edwards et al. (2014), who

405 demonstrated the effect of radiation in weakening the capping inversion, thus accelerating the

406 growth of the CBL.

407 Evening-transition LESs have a longer history. It seems to have been assumed that the resolution

408 suitable for convective boundary layers was also sufficient to represent the transition. Nieuwstadt

409 et al. (1986) used an abrupt cut-off of the surface heat flux. Sorbjan (1997) introduced and showed

410 the importance of a smoother reduction, which introduces a second timescale. Pino et al. (2006)

411 used LES to show that horizontal length scales become larger during the afternoon transition. Beare

412 et al. (2006) may have been the first to simulate the evening transition at fine resolution, with more

413 realistic fluxes. Early simulations had simplified representations of non-turbulent processes such

414 as radiation, which was shown to be important in light winds by Edwards (2009). Few LES models

415 have an interactive land surface, and the choice of surface boundary condition (flux or temperature)

416 has been controversial. Details of initialization and forcing were found to be important, e.g. Kumar

417 et al. (2010). Observed surface temperature was used by Rizza et al. (2013) to study the evening

418 transition, and they found TKE-decay power-law exponents of -2 early and -6 late in the 
transition, similar to those observed by Nadeau et al. (2011). El Guernaoui et al. (2019) explored

420 the TKE decay in the context of interacting time scales.

421 Both morning and afternoon transitions were simulated by Conzemius et al. (2008) for one day in

422 Oklahoma. In their LES model, they simulated very large relative contributions of shear-driven 423 entrainment to the total warming during the morning and afternoon. These are caused by the 424 realistic nature of the case. Profiles and TKE budgets are shown. Basu et al. (2008) simulated a 425 diurnal cycle from Wangara, emphasizing the low-level jet that appeared after the evening 426 transition. Their evening transition was abrupt, probably due to the lack of radiation and/or 427 subsidence in their setup. Full diurnal cycles were also simulated by Sharma et al. (2017), again 428 finding an abrupt evening transition without a representation of radiation and with no subsidence. 429 Both morning and evening transitions were included in the LES of Blay-Carreras et al. (2014b), 430 who emphasized the importance of the profiles above the growing boundary layer in the morning 431 and the forcing by subsidence in the afternoon. Darbieu et al. (2015) used a BLLAST case to set 432 the surface flux and initial conditions, and NWP model outputs to account for total advection 433 (including subsidence). Although the amount of TKE was different than in observations, and the 434 real conditions were much more complex than in the LES, the way that the TKE and the turbulence 435 structure evolved were very similar to the observations, showing a certain universality of the decay, 436 well reproduced by LES.

437 Figure 1 illustrates the evolving sophistication of coupled LES models. Itwas performed using the 438 large-eddy Met Office-NERC Cloud model (MONC) (Brown et al. 2015) coupled to the Joint UK 439 Land Environment Simulator (JULES) land-surface model (Best et al. 2011) and the Suite of 440 Community Radiative Transfer codes based on Edwards and Slingo (SOCRATES) radiation code 441 (Manners et al. 2015). The specifications of the simulation were chosen for visual clarity in the 
442 figure. The latitude was set as $57^{\circ} \mathrm{N}$ and a geostrophic wind speed of $8 \mathrm{~m} \mathrm{~s}^{-1}$ was prescribed. The

443 land surface was specified as short grass and the initial atmospheric profiles of temperature and 444 specific humidity were chosen to avoid the formation of cloud. The period shown begins on 2 445 March.

446 Direct numerical simulation (DNS) has recently become practical for application to atmospheric 447 problems. Mellado et al. (2016) simulated a free-encroachment case relevant to the late morning 448 transition. Fedorovich et al. (2017) performed DNS simulations relevant to the formation of the 449 low-level jet at the end of the evening transition.

\section{Transitions in Mesoscale Numerical Models}

451 Operational NWP models simulate transitions and the diurnal cycle regularly over large areas. 452 These models inherently simulate subsidence and advection. Radiation, boundary-layer physics, 453 clouds, and interaction of the atmosphere with the surface are parametrized. Climate-model 454 simulations likewise include many diurnal cycles under all kinds of conditions. However, research 455 specifically targeting transitions in mesoscale models is relatively rare in the literature. The 456 GEWEX Atmospheric Boundary Layer Study (GABLS) is a long-running project to improve the 457 simulation of the boundary layer in models and has proceeded through increasingly realistic 458 intercomparisons. Two of the three GABLS studies looked at diurnal cycles over land, and provide 459 the most complete view of mesoscale model performance during the transitions. The results show 460 considerable room for improvement. An overview of GABLS is given by Holtslag et al. (2013).

461 For GABLS2, Svensson et al. (2011) simulated a diurnal cycle from the CASES-99 experiment in 462 Kansas, USA. Many single-column models participated. Their behaviour during the transitions 463 was diverse. One conclusion was that choosing the most realistic or most useful boundary 
464 conditions and forcings is both difficult and critical. Specified surface temperatures were used as

465 the bottom boundary condition, and it became clear that the fluxes produced by the different 466 models for the same atmospheric and surface temperatures diverged. Heat flux during the morning 467 transition was too small and the boundary layer grew too slowly. This may have been due to too 468 little entrainment (see above), which also led to wind speeds that were too low. Different kinds of 469 boundary-layer scheme in the models had different kinds of errors, but no type of scheme was 470 clearly better for the whole diurnal cycle.

471 The GABLS3 study (Bosveld et al. 2014) benefited from the lessons learned in GABLS2. The case 472 was derived from measurements at Cabauw, The Netherlands. The single-column models included 473 land-surface and radiation modules, removing the need for specified lower boundary conditions. 474 Several of the conclusions of GABLS3 involved the land-surface formulations, which dominated 475 the transitions and stable boundary-layer behaviour. Another important conclusion was the 476 importance of longwave radiation from within the stable boundary layer (see above). Evening477 transition timing varied by $1.5 \mathrm{~h}$ among the models. In the morning, the simulated time of 478 crossover from downward to upward surface flux varied by 2 hours between models, and the 479 interval from crossover to onset of turbulence at $200 \mathrm{~m}$ was about half an hour too long.

480 Using a single-column model, Edwards et al. (2006) simulated two evening-transition cases, as 481 observed at Cardington Observed surface temperature was prescribed to the model as a lower 482 boundary condition. They emphasized the importance of specifying realistic advection. In both 483 cases, the simulated boundary layer was too shallow during the transition. They found limited 484 sensitivity to the resolution or the parameterization of turbulence in the stable boundary layer. At 485 the moderate wind speeds in these cases, longwave radiative cooling was a significant, but not the 486 dominant process in the development of the nocturnal boundary layer. Edwards (2009) described a 
487 case of very light winds (about $1 \mathrm{~m} \mathrm{~s}^{-1}$ ) and strong surface cooling and showed that radiative 488 cooling to the surface was the dominant process determining the evolution of the near-surface air 489 temperature through the transition. It was noted that the assumptions underlying standard surface490 layer similarity theory failed during the transition, leading to cold biases in operational forecasts in 491 such conditions.

492 Extensive observations of temperature profiles were examined by van Hooijdonk et al. (2017) to 493 study the growth rate of the surface-based temperature inversion, and compared with bulk and 494 single-column models of varying complexity. They found that the simplest models could not 495 reproduce the observations, because history effects were important. This reinforces the idea that 496 the boundary layer is not in equilibrium during some parts of the evening transition.

497 Mesoscale modelling for the BLLAST campaign also pointed out the importance of the land 498 surface. Lothon et al. (2014) and Couvreux et al. (2016) found variations of the vegetation among 499 different measurement sites to be an important contribution to variations in afternoon transition 500 timing. Angevine et al. (2014) devised a technique for making soil moisture match a limited-area 501 model better to produce more realistic simulations. Couvreux et al. (2016) found that a finer502 resolution NWP model (around $2 \mathrm{~km}$ grid spacing) resolves the vertical structures better than the 503 coarser models (around $10 \mathrm{~km}$ ), in particular a well-defined maximum of the water-vapour mixing 504 ratio that arises during the evening in the upper part of the residual layer due to fine-scale 505 advection. The finer- resolution model also provides a good simulation of the diurnal variability of 506 the turbulent kinetic energy, including its late afternoon decay, while the coarser model still shows 507 the right order of magnitude. 

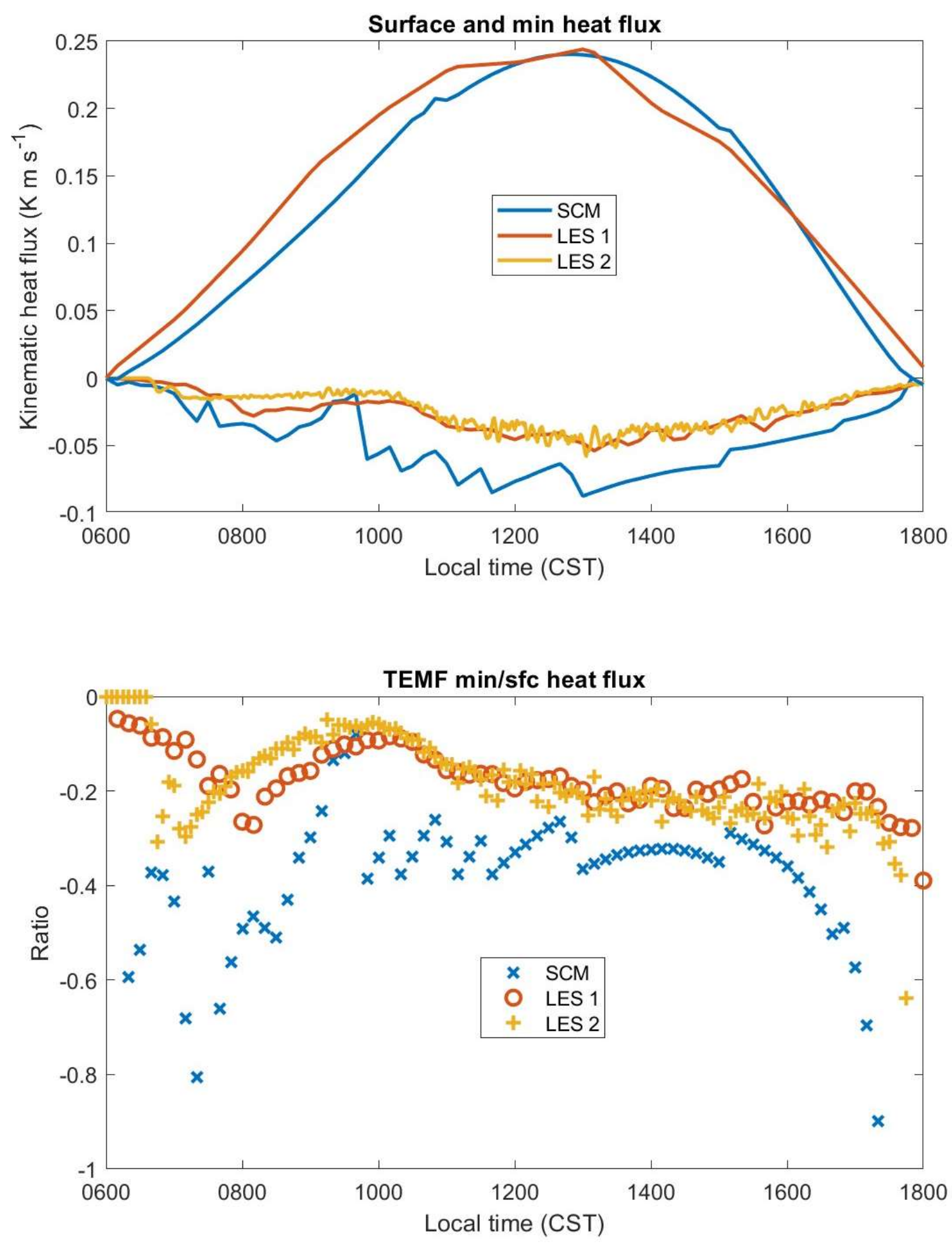

508 Fig. 3 (Top) surface and minimum sensible heat flux from a single-column simulation with the TEMF scheme and two

509 LES models for 6 June 2015 at the ARM SGP site in Oklahoma. Potential temperature flux is shown for SCM and

510 LES1, virtual potential temperature flux for LES2. See text for details. (Bottom) Ratio of minimum flux to surface

511 flux, one way of calculating the entrainment ratio. 
512 Diagnosing entrainment in mesoscale or NWP models is difficult because they rarely produce flux-

513 profile output by default. One exception is the Total Energy Mass Flux (TEMF) boundary-layer

514 scheme available in the Weather Research and Forecast model (WRF) (Angevine et al. 2018).

515 Figure 3 shows the diurnal cycle of the surface kinematic heat flux and the minimum flux in the

516 profile within the boundary layer for 6 June 2015 at the Atmospheric Radiation Measurement

517 Southern Great Plains site in Oklahoma. Along with the single-column model running TEMF, two

518 LESs of that day are also shown. The ratio of entrainment flux to surface flux is commonly used in

519 parameterizations, even though it is strictly applicable only to pure free convection driven from the

520 surface, and different methods of calculation yield different ratios (Conzemius et al. 2006; Liu et al.

521 2017). With those caveats in mind, the lower portion of Fig. 3 shows the entrainment ratio through

522 the diurnal cycle. TEMF has large ratios of the magnitude of entrainment flux to that of the surface

523 flux early and late in the day, consistent with some of the observational studies. TEMF also has a

524 relatively large ratio in midday. Breaks in the curve are due to limited vertical resolution in the

525 SCM. Both LESs show some of the same tendency to larger ratios in the morning and afternoon

526 transition periods. LES1 is from the U.S. Department of Energy LES Atmospheric Radiation

527 Measurement Symbiotic Simulation and Observation Workflow (LASSO) archive, simulation code

5280030 of 6 June 2015 (Gustafson et al. 2016a; Gustafson et al. 2016b). It has a 30-m vertical grid

529 spacing. LES2 was created by Glenn et al. (2019) using the System for Atmospheric Modeling

530 (SAM), with a vertical grid spacing $20 \mathrm{~m}$ above $600 \mathrm{~m}$.

\section{Outlook and Research Needs}

532 The progress in understanding ABL transitions over land in the last several decades has laid a firm

533 foundation for future research. Much could be learned from better-resolved LES modeling through

534 transitions, including all relevant processes, such as interactive radiation and an interactive ground 
surface. These processes are already represented in mesoscale models. Better understanding of cloudy boundary layers could also come from LES, and from mining existing datasets for cases that may have been discarded from previous analyses. Entrainment is still an open topic, especially its variation with wind shear, aerosol, and surface inhomogeneity. Non-column effects, such as terrain, coasts, and surface heterogeneity, must be considered as model grid sizes decrease. The proper representation of transitioning boundary layers in the grey zone or terra icognita (Wyngaard 2004; Efstathiou et al. 2016) requires exploration. The full energy balance at the surface and at the top of the boundary layer should be taken into account, including soil, canopy, and vegetation contributions to heat and moisture. Evolving measurement techniques can also contribute. Because real transitional boundary layers are influenced by even small surface or terrain variations, multiscale networks of observations have the most promise to provide useful insight.

\section{Acknowledgements}

The editors and referee are thanked for their careful reading and thoughtful comments, which improved the manuscript. M. LeMone is sponsored by NCAR, which is supported by the National Science Foundation.

\section{References}

Acevedo OC, Fitzjarrald DR (2001) The early evening surface-layer transition: Temporal and spatial variability. J Atmos Sci. 58(17):2650-2667.

Angevine WM (1999) Entrainment results including advection and case studies from the Flatland boundary layer experiments. J Geophys Res. 104(D26):30947-30963.

Angevine WM (2008) Transitional, entraining, cloudy, and coastal boundary layers. Acta Geophys. 56:2-20 doi:10.2478/s11600-11007-10035-11601.

Angevine WM, Bazile E, Legain D, Pino D (2014) Land surface spinup for episodic modeling. Atmos Chem Phys. 14(4):8165-8172.

Angevine WM, Grimsdell AW, Hartten LM, Delany AC (1998) The Flatland boundary-layer experiments. Bull Am Meteorol Soc. 79:419-431.

Angevine WM, Klein Baltink H, Bosveld FC (2001) Observations of the morning transition of the convective boundary layer. Boundary-Layer Meteorol. 101:209-227. 
Angevine WM, Olson J, Kenyon JS, Gustafson WI, Endo S, Sušelj K, Turner DD (2018) Shallow cumulus in WRF parameterizations evaluated against LASSO large-eddy simulations. Mon Weather Rev. 146:4303-4322.

Angevine WM, White AB, Avery SK (1994) Boundary-layer depth and entrainment zone characterization with a boundary-layer profiler. Boundary-Layer Meteorol. 68:375-385.

Baas P, Bosveld FC, Lenderink G, van Meijgaard E, Holtslag AAM (2010) How to design singlecolumn model experiments for comparison with observed nocturnal low-level jets. Q J R Meteorol Soc. 136(648):671-684.

Barbaro E, de Arellano JV-G, Ouwersloot HG, Schröter JS, Donovan DP, Krol MC (2014) Aerosols in the convective boundary layer: Shortwave radiation effects on the coupled landatmosphere system. J Geophys Res Atmos. 119(10):5845-5863.

Barlow JF, Dunbar TM, Nemitz EG, Wood CR, Gallagher MW, Davies F, O'Connor EJ, Harrison RM (2011) Boundary layer dynamics over London, UK, as observed using Doppler lidar during REPARTEE-II. Atmos Chem Phys. 11:2111-2125.

Barr AG, Betts AK (1997) Radiosonde boundary-layer budgets above a boreal forest. J Geophys Res. 102:29,205-229,212.

Basu S, Vinuesa J-F, Swift A (2008) Dynamic LES modeling of a diurnal cycle. J Appl Meteorol Climatol. 47:1156-1174.

Beare RJ (2008) The Role of Shear in the Morning Transition Boundary Layer. Boundary-Layer Meteorol. 129(3):395-410.

Beare RJ, Edwards JM, Lapworth AJ (2006) Simulation of the observed evening transition and nocturnal boundary layers: Large-eddy simulation. Q J R Meteorol Soc. 132:81-99.

Best MJ, Pryor M, Clark DB, Rooney GG, Essery RLH, Ménard CB, Edwards JM, Hendry MA, Porson A, Gedney N, Mercado LM, Sitch S, Blyth E, Boucher O, Cox PM, Grimmond CSB, Harding RJ (2011) The Joint UK Land Environment Simulator (JULES), model description - Part 1: Energy and water fluxes. Geosci Model Dev. 4(3):677-699.

Betts AK, Barr AG (1996) First International Satellite Land Surface Climatology Field Experiment 1987 sonde budget revisited. J Geophys Res. 101(D18):23,285-223,288.

Beyrich F, Goersdorf U (1995) Composing the diurnal cycle of mixing height from simultaneous sodar and wind profiler measurements. Boundary-Layer Meteorol. 76(999):387-394.

Blay-Carreras E, Pardyjak ER, Pino D, Alexander DC, Lohou F, Lothon M (2014a) Countergradient heat flux observations during the evening transition period. Atmos Chem Phys. 14(17):9077-9085.

Blay-Carreras E, Pardyjak ER, Pino D, Hoch SW, Cuxart J, Martínez D, Reuder J (2015) Lifted temperature minimum during the atmospheric evening transition. Atmos Chem Phys. 15(12):6981-6991.

Blay-Carreras E, Pino D, Vilà-Guerau de Arellano J, van de Boer A, De Coster O, Darbieu C, Hartogensis O, Lohou F, Lothon M, Pietersen H (2014b) Role of the residual layer and large-scale subsidence on the development and evolution of the convective boundary layer. Atmos Chem Phys. 14(9):4515-4530.

Blumberg WG, Turner DD, Cavallo SM, Gao J, Basara J, Shapiro A (2019) An Analysis of the Processes Affecting Rapid Near-Surface Water Vapor Increases during the Afternoon to Evening Transition in Oklahoma. J Appl Meteorol Climatol. 58(10):2217-2234.

Bony S, Stevens B (2018) Measuring Area-Averaged Vertical Motions with Dropsondes. J Atmos Sci. 76(3):767-783.

Bosveld F, Baas P, Steeneveld G-J, Holtslag AM, Angevine W, Bazile E, de Bruijn EF, Deacu D, Edwards J, Ek M, Larson V, Pleim J, Raschendorfer M, Svensson G (2014) The Third 
GABLS Intercomparison Case for Evaluation Studies of Boundary-Layer Models. Part B: Results and Process Understanding. Boundary-Layer Meteorol. 152(2):157-187.

Boutle I, Price J, Kudzotsa I, Kokkola H, Romakkaniemi S (2018) Aerosol-fog interaction and the transition to well-mixed radiation fog. Atmos Chem Phys. 18:7827-7840.

Brown AR, Cederwall RT, Chlond A, Duynkerke PG, Golaz J-C, Khairoutdinov M, Lewellen DC, Lock AP, Macvean MK, Moeng C-H, Neggers RAJ, Siebesma AP, Stevens B (2002) Large-eddy simulation of the diurnal cycle of shallow cumulus convection over land. Q J R Meteorol Soc. 128:1075-1093.

Brown N, Weiland M, Hill A, Shipway B, Maynard C, Allen T, Rezny M (2015) A highly scalable Met Office NERC cloud model. Proceedings of the 3rd International Conference on Exascale Applications and Software, Edinburgh, UK2015, City, pp. 132-137.

Busse J, Knupp K (2012) Observed Characteristics of the Afternoon-Evening Boundary Layer Transition Based on Sodar and Surface Data. J Appl Meteorol Climatol. 51(3):571-582.

Carter DA, Gage KS, Ecklund WL, Angevine WM, Johnston PE, Riddle AC, Wilson J, Williams CR (1995) Developments in UHF lower tropospheric wind profiling at NOAA's Aeronomy Laboratory. Radio Science. 30(4):977-1001.

Conzemius R, Fedorovich E (2006) Dynamics of sheared convective boundary layer entrainment. Part II: Evaluation of bulk model predictions of entrainment flux. J Atmos Sci. 63:11791199.

Conzemius RJ, Fedorovich E (2008) A case study of convective boundary layer development during IHOP-2002: Numerical simulations compared to observations. Mon Weather Rev. 136:2305-2320.

Coulman CE (1978) Boundary-layer evolution and nocturnal inversion dispersal - part I. Boundary-Layer Meteorol. 14:471-491.

Couvreux F, Bazile E, Canut G, Seity Y, Lothon M, Lohou F, Guichard F, Nilsson E (2016) Boundary-layer turbulent processes and mesoscale variability represented by numerical weather prediction models during the BLLAST campaign. Atmos Chem Phys. 16(14):89839002.

Darbieu C, Lohou F, Lothon M, Vilà-Guerau de Arellano J, Couvreux F, Durand P, Pino D, Patton EG, Nilsson E, Blay-Carreras E, Gioli B (2015) Turbulence vertical structure of the boundary layer during the afternoon transition. Atmos Chem Phys. 15(17):10071-10086.

de Lozar A, Mellado JP (2015) Mixing driven by radiative and evaporative cooling at the stratocumulus top. J Atmos Sci. 72:4681-4700.

Deardorff JW (1974) Three-dimensional numerical study of the height and mean structure of a heated planetary boundary layer. Boundary-Layer Meteorol. 7(81-106).

Driedonks AGM (1982) Models and observations of the growth of the atmospheric boundary layer. Boundary-Layer Meteorol. 23:283-306.

Edwards JM (2009) Radiative processes in the stable boundary layer: Part II. The development of the nocturnal boundary layer. Boundary-Layer Meteorol. 131:127-146.

Edwards JM, Basu S, Bosveld FC, Holtslag AAM (2014) The impact of radiation on the GABLS3 large-eddy simulation through the night and during the morning transition. Boundary-Layer Meteorol. 152:189-211.

Edwards JM, Beare RJ, Lapworth AJ (2006) Simulation of the observed evening transition and nocturnal boundary layers: Single-column modelling. Q J R Meteorol Soc. 132:61-80.

Efstathiou GA, Beare RJ, Osborne S, Lock A (2016) Grey zone simulations of the morning convective boundary layer development. J Geophys Res. 121:4769-4782. 
El Guernaoui O, Reuder J, Esau I, Wolf T, Maronga B (2019) Scaling the Decay of Turbulence Kinetic Energy in the Free-Convective Boundary Layer. Boundary-Layer Meteorol. 173(1):79-97.

Fedorovich E, Gibbs JA, Shapiro A (2017) Numerical study of nocturnal low-level jets over gently sloping terrain. J Atmos Sci. 74:2813-2834.

Garratt JR (1992) The atmospheric boundary layer. Cambridge University Press.

Garratt JR, Brost RA (1981) Radiative cooling rates within and above the nocturnal boundary layer. J Atmos Sci. 38:2730-2746.

Glenn IB, Feingold G, Gristey JJ, Yamaguchi T (2019) Quantification of the radiative effect of aerosol-cloud-interactions in shallow continental cumulus clouds. J Atmos Sci. submitted.

Grant ALM (1997) An observational study of the evening transition boundary layer. Q J R Meteorol Soc. 123:657-677.

Grimsdell AW, Angevine WM (2002) Observations of the afternoon transition of the convective boundary layer. J Appl Meteorol. 41(1):3-11.

Gustafson WI, Vogelmann AM, Cheng X, Endo S, Krishna B, Li Z, Toto T, Xiao H: 2016a, Description of the LASSO Alpha 1 Release, DOE Atmospheric Radiation Measurement Research Facility

Gustafson WI, Vogelmann AM, Cheng X, Endo SK, B., Li Z, Toto T, Xiao H: 2016b, LASSO alpha 1 data bundles. $36^{\circ} 36^{\prime} 18.0^{\prime \prime}$ N, 97 $29^{\circ}$ ' 6.0” W: Southern Great Plains Central Facility (C1), ARM Data Archive: Oak Ridge, Tennessee, USA

Ha K-J, Mahrt L (2003) Radiative and turbulent fluxes in the nocturnal boundary layer. Tellus. 55A:317-327.

Harvey NJ, Hogan RJ, Dacre HF (2013) A method to diagnose boundary-layer type using Doppler lidar. Q J R Meteorol Soc. 139:1681-1693.

Hogan RJ, Grant ALM, Illingworth AJ, Pearson GN, O'Connor EJ (2009) Vertical velocity variance and skewness in clear and cloud-topped boundary layers as revealed by Doppler lidar. Q J R Meteorol Soc. 135:635-643.

Holtslag AAM, Svensson G, Baas P, Basu S, Beare RJ, Beljaars A, Bosveld FC, Cuxart J, Lindvall J, Steeneveld GJ, Tjernstroem M, van de Wiel BJH (2013) Stable atmospheric boundary layers and diurnal cycles: Challenges for weather and climate models. Bull Am Meteorol Soc. 94:1691-1706.

Holtslag AAM, van Meijgaard E, De Rooy WC (1995) A comparison of boundary layer diffusion schemes in unstable conditions over land. Boundary-Layer Meteorol. 76:69-95.

Jensen DD, Nadeau DF, Hoch SW, Pardyjak ER (2016) Observations of Near-Surface Heat-Flux and Temperature Profiles Through the Early Evening Transition over Contrasting Surfaces. Boundary-Layer Meteorol. 159(3):567-587.

Kumar V, Svensson G, Holtslag AAM, Meneveau C, Parlange MB (2010) Impact of surface flux formulations and geostrophic forcing on large-eddy simulations of diurnal atmospheric boundary layer flow. J Appl Meteorol Climatol. 49:1496-1516.

Lapworth A (2006) The Morning Transition of the Nocturnal Boundary Layer. Boundary-Layer Meteorol. 119(3):501-526.

LeMone MA (1978) The Marine Boundary Layer, Workshop on the Planetary Boundary Layer. AMS, Boston.

LeMone MA, Angevine WM, Bretherton CS, Chen F, Dudhia J, Fedorovich E, Katsaros KB, Lenschow DH, Mahrt L, Patton EG, Sun J, Tjernstroem M, Weil J (2019) 100 Years of Progress in Boundary-Layer Meteorology, AMS Centennial Monograph. AMS, Boston. 
LeMone MA, Grossman RL, McMillen RT, Liou K-N, Ou SC, McKeen S, Angevine W, Ikeda K, Chen F (2002) Cases-97: Late-morning warming and moistening of the convective boundary layer over the Walnut River watershed. Boundary-Layer Meteorol. 104:1-52. LeMone MA, Ikeda K, Grossman RL, Rotach MW (2003) Horizontal Variability of 2-m Temperature at Night during CASES-97. J Atmos Sci. 60(20):2431-2449.

LeMone MA, Tewari M, Chen F, Dudhia J (2013) Objectively determined fair-weather CBL depths in the ARW-WRF model and their comparison to CASES-97 observations. Mon Weather Rev. 141:30-54.

Lenschow DH, Stankov BB, Mahrt L (1979) The rapid morning boundary-layer transition. J Atmos Sci. 36:2108-2124.

Liu C, Fedorovich E, Huang J (2017) Revisiting entrainment relationships for shear-free and sheared convective boundary layers through large-eddy simulations. Q J R Meteorol Soc. 144:2182-2195.

Liu C, Fedorovich E, Huang J, Hu X-M, Wang Y, Lee X (2019) Impact of aerosol shortwave radiative heating on entrainment in the atmospheric boundary layer: A large-eddy simulation study. J Atmos Sci. 76:785-799.

Lothon M, Lenschow DH, Mayor SD (2009) Doppler Lidar Measurements of Vertical Velocity Spectra in the Convective Planetary Boundary Layer. Boundary-Layer Meteorol. 132(2):205-226.

Lothon M, Lohou F, Pino D, Couvreux F, Pardyjak ER, Reuder J, Vilà-Guerau de Arellano J, Durand P, Hartogensis O, Legain D, Augustin P, Gioli B, Lenschow DH, Faloona I, Yagüe C, Alexander DC, Angevine WM, Bargain E, Barrié J, Bazile E, Bezombes Y, BlayCarreras E, van de Boer A, Boichard JL, Bourdon A, Butet A, Campistron B, de Coster O, Cuxart J, Dabas A, Darbieu C, Deboudt K, Delbarre H, Derrien S, Flament P, Fourmentin M, Garai A, Gibert F, Graf A, Groebner J, Guichard F, Jiménez MA, Jonassen M, van den Kroonenberg A, Magliulo V, Martin S, Martinez D, Mastrorillo L, Moene AF, Molinos F, Moulin E, Pietersen HP, Piguet B, Pique E, Román-Cascón C, Rufin-Soler C, Saïd F, Sastre-Marugán M, Seity Y, Steeneveld GJ, Toscano P, Traullé O, Tzanos D, Wacker S, Wildmann N, Zaldei A (2014) The BLLAST field experiment: Boundary-Layer Late Afternoon and Sunset Turbulence. Atmos Chem Phys. 14(20):10931-10960.

Mahrt L (1981) The early evening boundary layer transition. Q J R Meteorol Soc. 107:329-343. Mahrt L (2017) The near-surface evening transition. Q J R Meteorol Soc. 143:2940-2948.

Manners J, Edwards JM, Hill P, Thelen JC: 2015, SOCRATES (Suite Of Community RAdiative Transfer codes based on Edwards and Slingo) Technical Guide, UK Met Office Manninen AJ, Marke T, Tuononen M, O'Connor EJ (2018) Atmospheric boundary layer classification with Doppler lidar. J Geophys Res. 123:8172-8189.

Mellado JP, van Heerwarden CC, Garcia JR (2016) Near-surface effects of free atmosphere stratification in free convection. Boundary-Layer Meteorol. 159:69-95.

Nadeau DF, Pardyjak E, Higgins CW, Fernando HJS, Parlange MB (2011) A simple model for the afternoon and early evening decay of convective turbulence over different land surfaces. Boundary-Layer Meteorol. 141:301-324.

Nieuwstadt FTM, Brost RA (1986) The decay of convective turbulence. J Atmos Sci. 43(6):532546.

Nilsson E, Lohou F, Lothon M, Pardyjak E, Mahrt L, Darbieu C (2016a) Turbulence kinetic energy budget during the afternoon transition - Part 1: Observed surface TKE budget and boundary layer description for 10 intensive observation period days. Atmos Chem Phys. 16(14):8849-8872. 
773

774

775

776

777

778

779

780

781

782

783

784

785

786

787

788

789

790

791

792

793

794

795

Nilsson E, Lothon M, Lohou F, Pardyjak E, Hartogensis O, Darbieu C (2016b) Turbulence kinetic energy budget during the afternoon transition - Part 2: A simple TKE model. Atmos Chem Phys. 16(14):8873-8898.

Pennell WT, LeMone MA (1974) An experimental study of turbulence structure in the fairweather trade wind boundary layer. J Atmos Sci. 31:1308-1323.

Pietersen HP, Vilà-Guerau de Arellano J, Augustin P, van de Boer A, de Coster O, Delbarre H, Durand P, Fourmentin M, Gioli B, Hartogensis O, Lohou F, Lothon M, Ouwersloot HG, Pino D, Reuder J (2015) Study of a prototypical convective boundary layer observed during BLLAST: contributions by large-scale forcings. Atmos Chem Phys. 15(8):42414257.

Pino D, Jonker HJJ, vilà-Guerau de Arellano J, Dosio A (2006) Role of shear and the inversion strength during sunset turbulence over land: characteristic length scales. Boundary-Layer Meteorol. 121:537-556.

Price J (2019) On the formation and development of radiation fog: An observational study. Boundary-Layer Meteorol. 172:167-197.

Rizza U, Miglietta MM, Degrazia GA, Acevedo OC, Marques Filho EP (2013) Sunset decay of the convective turbulence with large-eddy simulation under realistic conditions. Physica A. 392:4481-4490.

Román-Cascón C, Yagüe C, Mahrt L, Sastre M, Steeneveld GJ, Pardyjak E, van de Boer A, Hartogensis $\mathrm{O}$ (2015) Interactions among drainage flows, gravity waves and turbulence: a BLLAST case study. Atmos Chem Phys. 15(15):9031-9047.

Savijarvi H (2006) Radiative and turbulent heating rates in the clear-air boundary layer. Q J R Meteorol Soc. 132:147-161.

Sharma V, Parlange MB, Calaf M (2017) Perturbations to the spatial and temporal characteristics of the diurnally-varying atmospheric boundary layer due to an extensive wind farm. Boundary-Layer Meteorol. 162:255-282.

Smith EN, Gebauer JG, Klein PM, Fedorovich E, Gibbs JA (2019) The Great Plains low-level jet during PECAN: Observed and simulated characteristics. Mon Weather Rev. 147:18451869.

Sorbjan Z (1996) Effects caused by varying the strength of the capping inversion based on a large eddy simulation model of the shear-free convective boundary layer. J Atmos Sci. 53:20152024.

Sorbjan Z (1997) Decay of convective turbulence revisited. Boundary-Layer Meteorol. 82:501515.

Steeneveld GJ, Wokke MJJ, Groot Zwaaftink CD, Pijlman S, Heusinkveld BG, Jacobs AFG, Holtslag AAM (2010) Observations of the radiation divergence in the surface layer and its implication for its parameterization in numerical weather prediction models. J Geophys Res. 115:D06107.

Stevens B (2002) Entrainment in stratocumulus-topped mixed layers. Q J R Meteorol Soc. 128:2663-2690.

Stull RB (1988) An introduction to boundary layer meteorology. Kluwer Academic.

Svensson G, Holtslag AAM, Kumar V, Mauritsen T, Steeneveld GJ, Angevine WM, Bazile E, Beljaars A, de Bruijn EIF, Cheng A, Conangla L, Cuxart J, Ek M, Falk MJ, Freedman F, Kitagawa H, Larson VE, Lock A, Mailhot J, Masson V, Park S, Pleim J, Söderberg S, Weng W, Zampieri M (2011) Evaluation of the diurnal cycle in the atmospheric boundary layer over land as represented by a variety of single column models - the second GABLS experiment. Boundary-Layer Meteorol. 140:177-206. 
Tennekes H (1973) A model for the dynamics of the inversion above a convective boundary layer. J Atmos Sci. 30:558-567.

Tucker SC, Senff CJ, Weickmann A, Brewer WA, Banta RM, Sandberg SJ, Law D, Hardesty RM (2009) Doppler lidar estimation of mixing height using turbulence, shear, and aerosol profiles. J Atmos Ocean Technol. 26:673-688.

Van Driel R, Jonker HJJ (2011) Convective boundary layers driven by nonstationary surface heat fluxes. J Atmos Sci. 68:727-738.

van Hooijdonk IGS, Clercx JH, Abraham C, Holdsworth AM, Monahan AH, Vignon E, Moene AF, Baas P, van de Wiel BJH (2017) Near-surface temperature inversion growth rate during the onset of the stable boundary layer. J Atmos Sci. 74:3433-3449.

van Ulden AP, Wieringa J (1996) Atmospheric boundary layer research at Cabauw. BoundaryLayer Meteorol. 78:39-69.

Wilczak JM, Gossard EE, Neff WD, Eberhard WL (1996) Ground-based remote sensing of the atmospheric boundary layer: 25 years of progress. Boundary-Layer Meteorol. 78:321-349.

Wildmann N, Rau GA, Bange J (2015) Observations of the Early Morning Boundary-Layer Transition with Small Remotely-Piloted Aircraft. Boundary-Layer Meteorol. 157(3):345373.

Wingo SM, Knupp KR (2015) Multi-platform Observations Characterizing the Afternoon-toEvening Transition of the Planetary Boundary Layer in Northern Alabama, USA. Boundary-Layer Meteorol. 155(1):29-53.

Wyngaard JC (1983) Lectures on the planetary boundary layer. In: Lilly DK and Gal-Chen T (eds.), Mesoscale Meteorology - Theories, Observations, and Models. D. Reidel, Dordrecht. Wyngaard JC (2004) Toward numerical modeling in the "Terra Incognita". J Atmos Sci. 61:18161826. 